no real anxiety in the minds of a patient's friends. Prompt interference by operation was the only treatment that offered any chance of saving the patient's life, but if a medical man had been consulted immediately after the onset of symptoms it is obvious that examination of the parts in a child aged six years would have been difficult and unsatisfactory, and the surgeon, however great his experience, might have failed to grasp the full gravity of the case in time to perform a successful operation.

Portman-street, W.

\section{DIFFICULTIES IN THE DIAGNOSIS OF SMALL-POX.}

By W. T. FREEMAN, M.D. DURH., F.R.C.S. ENG.

AN interesting paper on the above subject by Dr. W. M. Young appears in THE LANCET of June 7th, p. 1598. The following case also seems worth reporting.

An unhealthy-looking boy, 10 years old, was seen by $\mathrm{Mr}$. J. G. Braden of Reading on March 15th, 1902 . The patient was feverish and covered with a rash of the scarlatiniform type. There was some subsequent peeling but no albuminuria. The case was notified as one of scarlet fever. He soon became better of this attack, but on March 25th to the 27th he again became very ill. His temperature was high (from $100^{\circ}$ to $103^{\circ} \mathrm{F}$ ) and node-like swellings appeared on the front of the tibia and over the forehead and left orbit. He had also swelling apparently both in and around the left knee-joint. I saw the boy in consultation with Mr. Braden on April 3rd and he had still a high temperature and the swellings referred to were still in evidence, and he had developed additionally a profuse bulious rash; the vesicles or bullæ ran in size from that of a pin's head to near the diameter of a shilling-piece. The bullæ were principally grouped on the legs and buttocks, but some were also present on the arms and lower abdomen. Some of them had an umbilicated appearance and all were hæmorrhagic. They were commencing to dry up, but tests applied as carefully as possible practically proved them to be multilocular. The history of this second rash was that it first appeared as a papular one and subsequently became vesicular and bullous. There was a largish bulla on the left side of the tongue. 'The boy seemed to be very ill. He had all the appearances of a congenital syphilitic-typical upper incisors, flattened bridge of nose, scars at the angle of the mouth, \&c. He had good vaccination marks but had not been revaccinated. On the 7th he was much improved, the vesicles and bullæ were dried up into hæmorrhagic scabs, the swellings had nearly disappeared, and the temperature was normal. The patient recovered.

When I saw him on April 3rd I could not help wondering whether we were not dealing with an anomalous case of variola in a partially protected but specifically unhealthy child. The scarlatiniform rash, I thought, possibly might have been "a prodromal rash" and I was particularly impressed with the multilocular character of the lesions. The patient had been previously seen by the medical officer of health of Reading (Dr. A. Ashby) and we all determined to hold our hands as to variola. Dr. Ashby was not much in favour of small-pox and I declared myself more in favour of a peculiar bullous form of peliosis rheumatica than of variola, although the apparent multilocular character of the lesions was puzzling. Upon a second visit, paid two days later, I gave up the last shred of an idea of its having been the more formidable infectious disorder. I believe that the whole condition was a developmental erythema-an erythema of the nodose type passing on through stages to a bullous type of rheumatic purpura. An unhealthy subject amidst not the best of surroundings and with a syphilitic taint, the boy was no doubt predisposed to the anomalies, both subjective and objective.

It is right to add that Mr. Braden. the patient's original medical attendant, is still inclined to think that the primary rash was scarlet fever and that the svmptoms and rash of ten days later were of distinct origin. It should also be added that as the boy improved he was vaccinated and a full reaction resulted.

Reading.

\section{A ettiruror}

\section{HOSPITAL PRACTICE,} BRITISH AND FOREIGN.

Nulla autem est alia pro certo noscendi via, nisi quamplurimas et morborum et dissectionum historias, tum aliorum tum proprias morborum et dissectionum historias, tum aliorum tum proprias uorb., lib. iv., Procemiurn.

\section{HOSPITAL FOR SICK CHILDREN, GREAT ORMOND STREET.}

A CASE OF BILATERAL STRANGULATED HERNIA IN AN INFANT.

(Lnder the care of Mr. T. H. KELLOCK.)

Is infants under the age of one year it is rare for strangulated inguinal hernia to occur, but it must be extremely rarely that in a young child strangulation should occur in hernix on both sides of the body. In THE LANCET of June 1st, 1901, p. 1536, we quoted some statistics as to the occurrence of strangulated hernia in infants, to which we refer our readers.

An infant, aged 10 weeks, was admitted to the Hospital for Sick Children, Great Ormond-street, on March 8th, for irreducible right inguinal hernia. The mother stated that when the child was seven weeks old she first noticed a swelling in the right groin; for this she attended the outpatient department and circumcision was performed on March 4th; at that time the hernia disappeared when the child was quiet and still. She had never noticed any swelling on the left side On the 6th the swelling was noticed to become larger and more tense ard could not be got back; it remained down for the two following days, during which the child was very fretful and vomited occasionally after taking the bottle. On admission the patient appeared to be a healthy well-nourished child but very fretful, crying almost continuously; he had a hernia in the right inguinal region which was found to be irreducible under an anæsthetic; it was therefore operated on and was found to contain a knuckle of small intestine tightly constricted at the inguinal ring, which was very small. The bowel was dark blue in colour and deeply marked where it had been constricted. There was an almost total absence of fluid in the sac. Before the bowel could be reduced a rather free incision had to be made in the constriction at the neck of the sac and after it had been reduced the sac-to which the vas deferens was closely adherent-was ligatured at the neck and removed. Two silk sutures were used to close the inguinal canal. The external wound was sutured and dressed with gauze and cullodion.

The child progressed favourably but cried a great deal. On March 10th a hernia was found in the left inguinal region which was reduced with some difiiculty. On the 18th the wound was healed and the stitches were removed. On this day the hernia on the left sile was present again but was easily reduced. On the 19 th the child was discharged wearing a skein truss on the left side. He was re-admitted four days later, the hernia in the left groin having been irreducible for five hours. On the evening of that day an operation was performed and there was found an almost precisely identical condition to that which had been seen on the right side. The same treatment was adopted, the wound healed rapidly, and he was again discharged. When seen some time afterwards in the out-patient department the condition was quite satisfactory; the wounds were soundly healed and there was no sign of return of either hernia.

Remarks by Mr. KELLOCK.-Except for the rurity of strangulated hernia occurring on both sides at so short an interval there is little in this case calling for comment. The child had probably a partially closed funicular process of peritoneum on both sides and into these successively the almost constant pressure from crying drove a knuckle of intestine. The inguinal rings on both sides were very small and had to be rather freely incised before the bowel could be reduced. This is probably always the most difficult part of the operation in an infant and it is better to be free with the incision rather than to use any force in attempting to 